\title{
Evolution and Sustainability: What Is It Difference?
}

\author{
Arkady Martynov \\ International Institute for Social Development, \\ Institute of Economics, Russian Academy of Sciences, \\ 101000, Moscow, Russia
}

DOI: https://doi.org/10.36941/ajis-2021-016o

\begin{abstract}
This article is devoted to the fundamental interdisciplinary problems of evolution and sustainability. From a contemporary standpoint, the author assesses the persisting notions of social and, in particular, economic evolution. An appropriate alternative to these notions presents the framework concept of integrative sustainable development, enshrined in the UN Agenda 2030. Based on the recognized integrative vision of the sustainability problem, it is advisable to extend this concept to the entire process of transformation of society as a social system. It can be named sustainable overall social transformation (SOST). The fundamental properties of SOST and the role of key actors in its provision are revealed. As follows from the study, the current implementation of SOST will be largely associated with non-evolutionary changes. The final conclusion concerns the substantial difference between the sustainable and the preferable evolutionary trajectories of the overall social transformation in the long run.
\end{abstract}

Keywords: evolution, sustainability, resilience, corporate business, eco-system business, state agencies

\section{Introduction}

Until now, the problem of evolution remains in the focus of comprehensive researchers. As it known, in the past, for a long time in the scientific world, the general theory of social evolution, including its various modifications, occupied a leading position. Suffice it to mention the contributions of Herbert Spencer and Talcott Parsons (Spencer, 1885; Parsons, 1968). This theory had a huge positive impact on many areas of research, predetermining their orientation towards finding a path to overall societal progress.

However, in relation to the dynamic modern epoch, objectively characterized by multilateral, multidirectional and often differently sign changes, the orthodox theory of social evolution has lost the necessary measure of realism. The same obviously applies to its Marxist version (the so-called historical materialism). A compelling argument for this conclusion is provided in the acclaimed writings of Anthony Giddense (Giddense, 1983, 1984).

Apparently, the most serious shift in the renewal of the general paradigm of evolution is associated with the emergence of the well-known concept of institutional evolutionism. Its adherents usually emphasize the broad possibilities of evolutionary adaptation of contractual and other institutions on the basis of a constant increase in their diversity to changing and emerging new social preferences (e.g., Hodgson, 2015). But, unfortunately, one cannot really count on the very 
approximation of the previously established trajectories of institutional changes to the trajectories corresponding to the desired ordinal changes in the main social fields. This requires purposeful actions of the specific actors including state agencies in the course of the needed reforms, which are far from smoothly gradual in time and space.

As follows from a huge number of specific studies (including anthropological ones), Darwin's theory of biological evolution is directly related only to some local social practices, in particular, to traditional household activity. This is understandable. In the biological world, there are no states and national (supranational) elites, parties and special services and, moreover, no coalitions with special interests, there are only separate herds. The life activity cycle of significant social subjects cannot be decomposed into the simplest components, similar to the life cycle of the existence of certain groups of biological species.

It should be added that the phenomena of collective action and conflicts of interest are simply bypassed in existing theories of social and institutional evolution. The same applies to many historical cataclysms, which present inexplicable phenomena from the standpoint of traditional evolutionism. The charismatic example: the conquests of Genghis Khan in the 13th century.

A special issue concerns the coverage of the problem of evolutionary development in economic science. The feasibility of resorting to the idea of natural selection in relation to the market environment has definitely been proven over time (e.g., Alchian, 1950; Metcalfe, 1994). However, the hypothesis about the factor of market selection as an exclusive determinant of economic development has not been verified, at least for three very important reasons. First, the action of the factor of power, due to the non-economic advantages of some market agents over others. Second, the autonomous technological changes are of great importance. Third, non-stationary, often just shocking, demographic shifts and associated migration shifts on a national, regional and global scale. These factors especially intensified in the run-up to and after the global crisis in 2007-2009. Therefore, the applied analytical models of the evolution of market sectors have simply become inadequate to realities. And, apparently, the theory of evolutionary economic determinism, directly based on the famous fundamental research of Richard Nelson and Sydney Winter (Nelson \& Winter, 1982), has now become the property of history.

Evidently, one cannot ignore the widely popular concept of eco-system business (ESB), based on the hypothesis of equitable effective cooperation of producers, consumers, suppliers and other agents within a certain eco-system, similar to the union of biological species (Moore, 1993). This concept directly connects with the paradigm of biological evolution according to Darwin (Moore, 1993, 1996; Adner, 2006, 2017). And, perhaps, one can agree that real-life business networks, referred to as ecosystems, develop on the basis of self-organization and mutual evolution (Iansiti \& Levien, 2004). At the same time, the market barriers to the emergence of modern ecosystem business networks are quite obvious, which have arisen, as it were, around digital platforms in the presence of significant resource constraints and the well-known dependant behavior of many ESB agents who follow the leaders (Pidun et al., 2020). It is quite understandable that ESB, as a sector in terms of its market potential, is significantly inferior to large corporate business, the leading position of which preserves beyond doubt.

In addition to the above, it is appropriate to focus on the widespread simplified interpretation of evolution in numerous studies dealing with extremely diverse problems of economic and social development. In essence, evolution identifies as a normal, non-crisis long-term development. All predetermine non-evolutionary changes except for revolutionary explosions are considered as sporadic "mutations", the neutralization of which is intended to be carried out in the process of routine regulation mainly by government. Proceeding from such a super utilitarian approach, the established inertial trends of social development present the core standards of evolution. It is worth noting that the interpretation of evolution as a universal type of development manifests in an apologetic justification for further social progress on the basis of outdated capitalism of the last century with its unacceptable institutional flaws.

An unambiguous alternative to the preserving widespread simplification of social evolution is 
the framework Concept of integrative sustainable development, enshrined in the UN Agenda 2030. In accordance with it, the future transformation of society is designed to be focused on achieving the goals and targets of sustainable development (SDG). In essence, achieving SDG requires a turn towards sustainable societal progress accompanied by economic, political, status, environmental, climatic, and other quantitative and qualitative fundamental transformational shifts (Sachs, 2015). They presuppose a break in the previously established transformational trajectories due to the actions of social actors that are adequate in depth and scale. Suffice it to say about the grandiose required shifts to overcome the climate threat, as well as the threat of Pandemics like Covid-19. Certainly, this kind of metamorphoses is not consistent with traditional stereotypes according to the evolutionary paradigm.

Based on the recognized integrative vision of the sustainability problem, it is advisable to extend the framework Concept to the entire process of transformation in society as a social system (Giddings et al., 2002; Fisher \& Rucki, 2017). Obviously, an adequate understanding of this phenomenon is incompatible with the widespread use of the term "sustainable" as a buzzword, attributed to any stable temporal and spatial processes.

Let us try, at least as a first approximation, to answer the question posed in the Title. To this end, the two following parts of the article reveal the fundamental properties of a sustainable overall social transformation and the role of the key actors in its provision. Discussion issuers are presented in the last part. As a result, the final conclusion has formulated which concerns the substantial difference between the sustainable and the preferable evolutionary trajectories of the overall social transformation.

\section{Methodology. Sustainable Overall Social Transformation: The System Design.}

Proceeding from the reformist ideology, the immanent feature of the desired development of society concludes in its overall progress, which can be defined as sustainable (Sachs, 2015). This kind of progress characterizes by economic, political, status, ecological, climate and other quantitative and qualitative parameters that are assumed to be sustainable in accordance with the accepted criteria due to the overall societal development.

It is quite logical to turn to the idea of universal or system sustainability, inherent to one degree or another in all social practices, and not only mediating the relationship between society and its environment (Giddings et al., 2002; Fisher \& Rucki, 2017). The methodological approach based on this idea allows fully capturing the interconnected processes of sustainably reproducible changes in society. The integrative studies of sustainable development in main interrelated areas in the contemporary era of digitalization really follow such system approach (TWI2050, 2018; Sachs et al., 2019; TWI2050, 2019; WBGU, 2019).

Well-known investigations of socio-ecological systems (SES) also fit into the mainstream of the universal view of sustainability. It can be argued that the formation of the SES framework concept helped to build a bridge between biophysical and social scientific research (Berkes \& Folke, 1994; Ostrom, 2010; Partelow, 2017). Moreover, the methodology based on this concept has been successfully used for a long time in the technology of ecological design. However, the scope of its application seems to be deliberately limited, since in most cases the successful functioning of SES becomes possible under favorable external conditions, market (financial) and others.

Following the indicated approach, two unifying and interdependent criteria conditions for sustainable reproducibility within the entire social system can be defined (Martynov, 2020).

The first of these conditions consists of sustainable, essentially rational production and consumption of existing basic resources - tangible and intangible, human and, of course, natural, based on the recognized SDG in accordance with the Agenda. In addition to this, in the future, it will be advisable to incorporate new targets that predetermine the trajectories of sustainable reproduction and consumption of structure-forming resources in their renewed composition. Consequently, the list of indicators for an implementation of the Agenda will expand, representing 
estimates of the degree of proximity to SDG (OECD, 2019; 2020 Comprehensive Review, 2020)

The second condition concerns the sustainably reproducible allocation and distribution of resources, incomes and capital at the macro and other levels of the system hierarchy in accordance with the existing criteria of progress. As applied to the economic field, this means a long-term spatial and temporal normality-balance of the main resource, material and financial proportions of output in the line of sustainable progress. The same applies to the proportions of distribution, in particular relating to internal and external migration flows.

Truth, it must be admitted that the indicated conditions of system sustainability cannot be met in full if the factors of global instability persist far beyond the boundaries of the economic field. Suffice it to point out the most resonant media factors: the still tremendous destabilizing influence of US debt on the entire global development and the spread of bitcoin as a world currency (Sneader \& Singhal, 2021). In addition, the functioning of the market-based financial system in the United States, the United Kingdom and some other countries, which induces speculative financial turnover, is undoubtedly a fundamental institutional factor that violates global system sustainability. Also, a significant institutional obstacle to the establishment of a long-term stable world order concludes in the absence of a long-overdue reform of the international monetary system.

The criterion conditions for universal sustainability are called for predetermining the choice of further trajectories of overall social transformation. It can be named sustainable overall social transformation (SOST).

SOST design assumes adequate positioning in time and space of the required resource, institutional and organizational-behavioral shifts, taking into account the influence of external exogenous factors (technological, demographic and climatic changes) and interactions on the "adjacent" fields of social action. Along with this, among the possible alternatives, it is necessary to choose transformation trajectories proceeded from the condition of adaptation as resilience to the objectively unsustainable changes (Gallopin, 2006, Folke, 2016). They include exogenous technological, demographic and climate changes, cyclical and other market fluctuations, sporadic political upheavals, and multiple social conflicts. The problem of neutralizing the impact of instability in the future is recognized as central in the course of making strategic decisions and implementing regulatory mechanisms with the participation of specific actors (Transformation towards, 2018; OECD, 2020).

The key issue presents ensuring elastic adaptation to new technologies in the foreseeable future (e.g., Körner et al., 2018; Acemoglu \& Restrepo, 2020). As evidenced by numerous facts, the consequences of new automation, as well as the use of robots and technologies based on artificial intelligence are now fully manifested in labor markets. There is a sharp reduction in human labor in various areas of routine activity with an ordinal increase in the number of highly qualified personnel of the new era, distinguished by the intellectual abilities of independent analysis, critical thinking and the ability to informally solve specific problems.

The fateful problem of employment in the context of accelerating automation and digitalization is absolutely insoluble only on a market basis. To ensure system sustainability, there is no alternative to the need to create financial and other conditions for a radical increase in employment in social sectors in the coming post Pandemic period, where a vast territory will appear for the use of technological innovations as purely social benefits. This is especially true for sectors such as education, health and local social work. Also, a huge growth potential for employers, including intellectuals, observes in the non-market environmental sector, covering a wide variety of activities.

\section{Result: Sustainable Overall Social Transformation: The Key Actors, Positioning of their Performance Associated with the Non-Evolutionary Changes}

Until now, in a huge number of mass publications in various countries, as well as in training courses, the mission of achieving the SDG is unconditionally assigned to corporate business. This point of view objectively reflects the profound shift that has taken place in the activities of large corporations 
towards the recognition of sustainable development ideology (e.g., Porter \& Kramer, 2011; Beyne, 2020). It is enough to turn to public sustainability reports of well-known companies in recent years (SP Global, 2021).

At the same time, the propagandized ideas about the miraculous role of big corporate business in providing sustainability, based on the principles of social responsibility and a new corporate culture, cause unequivocal rejection. So, judging by the real experience (in particular, in Russia), such kind of charitable activity is distinguished by a deliberately limited scale. Dramatically increasing this scale simply runs counter to the goals of maximizing financial results and improving / maintaining competitive position, which remain the top-priority for successful modern corporations.

The researchers reasonably draw attention at the worthy contribution of existing small and medium-sized enterprises (SMEs) to achieve sustainable progress (e.g., Tonis, 2015). This, for example, is evidenced by the choice of consumers in many countries in favor of ecologically perfect and exclusive food products and furniture, produced by individual entrepreneurs. In the short term, successful diffusion of green and, in particular, circulation technologies in SMEs has predicted in many countries and regions (Gregurec et al., 2021). However, when assessing such forecasts, one should take into account the obvious segmentation limitations for development of the indicated sector.

The digitalization, the softening of industrial processes and the diffusion of green (circulation) technologies expose the possibility of a radical expansion of the production, the provision of market and social services, as well as the consumption of resources in accordance with the imperatives of sustainable development. This conclusion confirms by a variety of empirical experiences, in particular, regarding the use of block chain technology in the fintech sector to ensure cyber security as a prerequisite for the stable development of a significant part of the trade sector (FernandezVazquez et al., 2019). It is also fundamentally important that corporate eco-social programs implemented in the new technological environment make a possibility to carry out a positive financial effect (MGI, 2021).

At the same time, it would be incorrect to absolute the effect of the influence of technological and accompanying organizational and production shifts on economic and other social activity from the standpoint of approaching the trajectory of sustainable development. No technological reboot guarantees a balance of the proportions of output and distribution that emerge as a result of the interactions of various institutions and actors strictly within the boundaries of the economic and other societal fields.

Also, it certainly does not seem to be a panacea to expand and qualitatively improve ESB in its current digital framework for a system solution of the problem of balanced and proportional sustainable development. As noted earlier, expectations of an increase in the relative importance of this sector in comparison with large corporate and other sectors seem to be moderate. However, it is difficult to question about the significant and positive contribution to sustainable progress that ESB is already making, operating on the principles of equity and transparency. Its growth uniquely contributes to sustainable progress in a wide variety of sectors. Moreover, the expanding of outperforming corporations (such as Tencent, Microsoft, and Amazon), which now partially incorporates eco-system business networks, are increasingly aligned with the sustainability items (Dietz et al., 2020). The large corporations provide valuable contributions to sustainable progress just through patronage of ESB networks.

It should be admitted: the limited potential of corporate business and other entrepreneurship in achieving SDG is called upon to be replenished through public regulation. Its main actors are civil organizations and the state itself, whose leading role as a system regulator remains indisputable.

Achieving sustainable development imperatives in terms of indicators of production and consumption of resources, the activity of social sectors and the resolution of humanitarian problems is impossible without the active participation of state agencies, as well as non-state civil organizations. Thus, practical experience confirms the crucial role of public-private partnerships in the implementation of environmental and many accompanied projects. 
To an equal extent, government intervention is required to fulfill the conditions for a sustainable balance of the proportions of output and distribution. For this purpose, the stabilization monetary and financial policies should be complemented by long-term political decisions that initiate favorable shifts in the development of economic and social sectors towards achieving and further maintaining SOST.

The state also decisively bears efforts to fulfill the condition of resilience according to SOST. One recognizes the paramount importance of an adequate government policy to neutralize climate shocks.

Besides, the exclusive role of the state and its competent agencies in the system coordination of decisions to implement sustainable overall social transformation is beyond doubt. At the national level, the result of such coordination concludes in ensuring a guarantee of maintaining an acceptable level and quality of life.

A growing need for national sustainable development strategies has observed (Martynov, 2021). They will provide an adequate spatial-temporal positioning of really achievable trajectories of transformational changes at the macro, sector and regional levels in the direction to SDG.

At the same time, active and simultaneously flexible public regulation in the relation to SDG should not impede positive initiative decisions of market and social entrepreneurs. The existing experience of economic transformation in a significant number of countries testifies in favor of the following assumption. The acting leading companies are able to achieve optimal financial and other market results in line with their long-term strategy, the cumulative effect of which at the system level will not violate the acceptable proportions of output and distribution in accordance with the conditions of sustainability. Such opportunity can be realized if an adequate macro, structural and regional long-term policy has implemented to ensure adaptation to exogenous changes technological, demographic, climate, as well as the alignment of corporate and other entrepreneurial strategies with the government strategic course in accordance with the principle of compromise equilibrium (Nash-type equilibrium).

Thus, the two floors positioning of SOST as a process of system changes seems legitimate. First, it occurs in the sphere of stabilized national development, where the actors of public regulation albeit in close cooperation with national business are dominant. Only on this basis a successful transformation in the sphere of accelerated sustainable progress can take place, to a decisive extent conditioned by the initiative activities of the leading market and non-market agents.

It is reasonable to assume that transformational changes in the direction of SOST will be largely associated with "breaks" of gradualness (illustrative scheme 1). So, the required rapid approximation to SDG in many countries, mainly due to public regulation (on the ist floor of SOST), presupposes notoriously discrete structural changes compressed in time. The same kind of changes has, most likely, been produced by the active stabilization policy including discrete measures in the upcoming period of transition to the next New Normal (OECD, 2020), as well as by the resilience decisions regarding the Pandemic, climate deterioration, etc.

The expectations of non-evolutionary changes are also quite understandable if SOST is implemented on its 2nd floor. As follows from recent studies (Sadollah et. al., 2020), the implementation of proactive corporate and other entrepreneurial projects in the field of sustainable development entails ordinal, not at all incremental resource and organizational changes. Even more importantly, the growing need for resilience to unsustainable shocks from the side of business leaders has been expressed in multi directional and differently sign changes: incremental and discrete, uniform and uneven, far different from evolutionary type changes in its accepted understanding (OECD, 2020; Beninger \& Francis, 2021). 
Scheme 1: The performance of key actors in SOST at national level associated with the nonevolutionary changes. Two floors positioning.

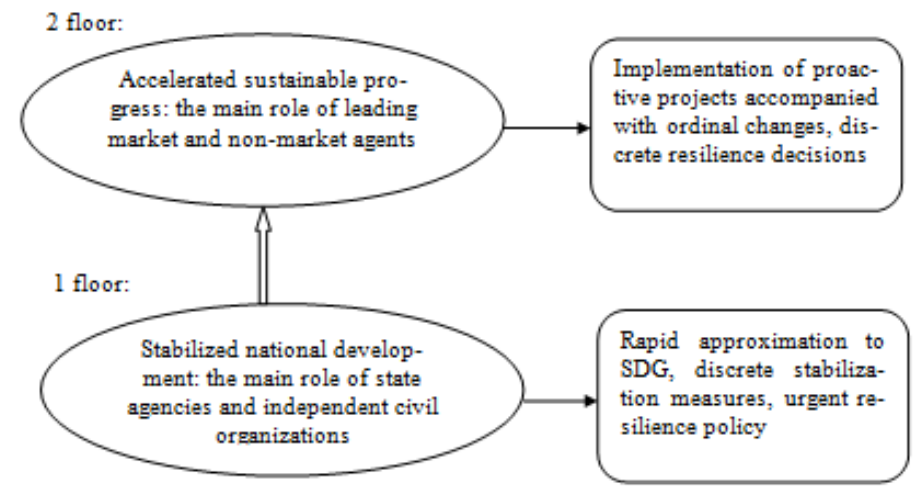

\section{Discussion and Conclusions}

The framework discussion issue concerns the predictability of the near future. The Pandemic has caused unprecedented damage to the entire human society, casting doubt on its further progress. As a consequence, a popular opinion about the predetermine uncertainty of further development, characterized by the prevalence of chaotic social perturbations, still remains. One cannot agree with such outcome. The observed revival in the market and social sectors of most industrialized, Western and non-Western countries presents a good reason to hope for the restoration of positive trends in favor of sustainable progress.

By the beginning of this decade, the valuable preconditions for positive shifts in the main fields of social action are taking shape (Martynov, 2019). They are called upon to manifest themselves in a radical weakening of the destructive factor of power in the world and national arenas, when economic and overall social progress in most countries will be achieved mainly through technological innovations, own production capabilities and growing human capital. Then there will be an opportunity for effective support the long-term development of lagging countries.

In the case of a positive scenario of world development in the coming future, the transition to SOST in advanced countries will become real, although not fully feasible due to the likely preservation of a high weight of external, global and regional, unsustainable processes. In these countries, the achievement of the accepted imperatives of sustainable development in most areas actually took place or is likely to occur along with the provision of entire system balance at macro, sector and regional levels.

In the long run, if sustainable progress will be asserted, there are reasons to expect a weakening of structural shifts of a deliberately non-evolutionary nature. Long-term reproduction of system sustainability will present consistently progressive movement towards achievable frontiers, based on the identified opportunities. Grounded on the well-known criteria of optimal inter-temporal ratio of costs and outputs, the transformation of social macros as a system on a stable and plausible longterm trajectory is preferable. In addition, the fundamental interest of market and social entrepreneurs in coordinated predictable behavior that is best matched by plausible institutional change should be taken into account (Ostrom, 2000).

Thus, the possibility of approaching the trajectories of national sustainable development to a hypothetical preference evolutionary trajectory, characterized by exclusively incremental transformational changes, will become quite real (as reflected in scheme 2).

At the same time, based on the existing social realities, the achievement of an all-encompassing dominance of the factors of evolutionary development seems to be illusory; in any case, within the 
foreseeable perspective. So, contrary to perfectionist projection predictions, the spread of the evolutionary trajectory of transformation, which distinguishes the development of modern ecosystem business, to the high-tech sector as a whole, like other sectors, will unlikely to take place in majority of modern countries. To a decisive extent for a completely prosaic reason: such a system metamorphosis is incompatible with the preservation of the market power of large corporations as oligopolies and, ultimately, with the interests of the ruling elites and other strata on the upper floors of the status pyramid. Apparently, uneven trends of institutional change, associated with discrete reforms (such as in relation to the SOE in emerging economies), will continue in the main economic sectors.

It is equally reasonable to focus on the following circumstance. With any future development trends, even the most favorable ones, the importance of effective adaptation as resilience by the key actors to unsustainable changes will remain crucial. All of these actors, including corporate business, ESB, state agencies, independent civil organizations, will need to master this kind of adaptive behavior. In this regard, it seems appropriate to turn to a convincingly substantiated theorem: the richer the artifact structures of a society, the higher the likelihood that new problems will be successfully solved (North et al., 2009).

In the long run the widespread use of adaption tools for resilience is likely to be associated with sufficient deviations from the previously established SOST trajectory. In turn, it will, albeit temporarily, move away from the hypothetical preferential evolutionary trajectory (scheme 2).

Scheme 2: Relationship between sustainable and evolutionary overall social transformations: approaching $(\rightarrow)$ and reverse $(\leftarrow)$.

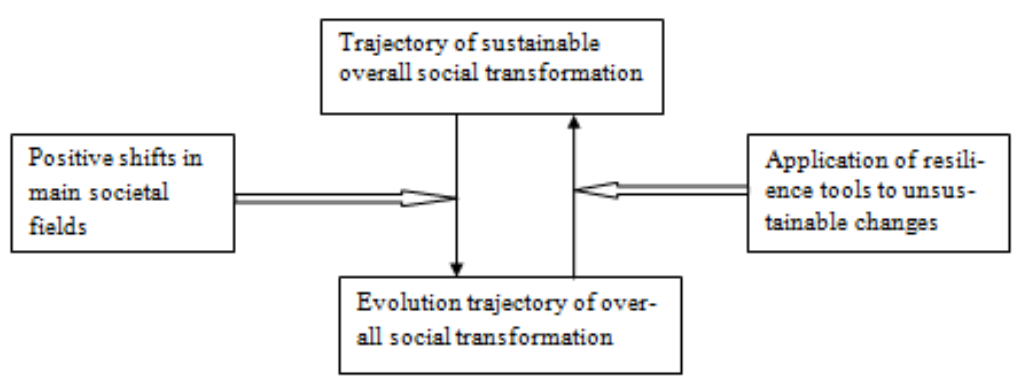

Despite all the above, let us preserve a realistic point of view. It would be incorrect to ignore the possibility of unsuccessful fulfillment of the positive scenario of world development and the implementation of alternative scenarios instead.

Against the background of the impressive global and other changes in nowadays, the stagnation scenario, projected on the basis of the prolongation of the trends in the past decade, might be considered as hypothetical. This scenario accompanies with unacceptably weak progress in sustainable development in most areas. It can be assumed that the trajectory of overall social transformation will be temporarily close to the so-called "dead-end" evolutionary one. It is absolutely at odds with the trajectory of sustainable transformation.

The negative scenario including many various versions seems much more expected. The recognized version of this scenario assumes a radical strengthen in geopolitical confrontation, which would probably be expressed in international military conflicts with the use of mass destructive weapons (thermonuclear, neutron, biological). With such a development of events, evidently the non-evolutionary shifts will prevail. In addition, this kind of shifts will inevitably continue in the event of a further return to normal development and, moreover, approaching anew to SDG. Therefore, the projected trajectory of overall social sustainable transformation will be unattainably far from evolutionary-type trajectory for a long time. 
Thus, taking into account pessimistic expectations the final conclusion does not call into question: the substantial difference between sustainability and evolution would be significant!

\section{References}

2020 Comprehensive Review Proposals Submitted to the 51st session of the United Nations Statistical Commission for its consideration. (2020). United Nations. Available at: https://unstats.un.org/sdgs/iaeg-sdgs/2020-comprev

Acemoglu, D., \& Restrepo, P. (2020). Robots and Jobs: Evidence from US Labor Markets. The Journal of Political Economy, 128, 6: 2188-2244. http://www.journals.uchicago.edu/t-and-c

Adner, R. (2006). Match your innovation strategy to your innovation ecosystem. Harvard Business Review, 84, 4: 98-107. https://hbr.org/2006/o4/match-your-innovation-strategy-to-your-innovation-ecosystem

Adner, R. (2017). Ecosystem as Structure: An Actionable Construct for Strategy. Journal of Management, 43, 1: 3958. DOI: $10.1177 / 0149206316678451$

Alchian, A. (1950). Uncertainty, Evolution, and Economic Theory. The Journal of Political Economy, 58, 3: 211-221. http://dx.doi.org/10.1086/256940

Beninger, S., \& Francis J.N.P. (2021). Resources for Business Resilience in a Covid-19 World: A Community-Centric Approach. Business Horizons, available online 24 February. https://doi.org/10.1016/j.bushor.2021.02.048

Beyne, J. (2020). Designing and Implementing Sustainability: An Integrative Framework for Implementing the Sustainable Development Goals. European Journal of Sustainable Development, 9, 3: 1-12. Doi: 10.14207/ejsd.2020.v9n3p1

Berkes, F., \& Folke, C., ed. (1998). Linking Social and Ecological Systems: Management Practices and Social Mechanisms for Building Resilience // N.Y.: Cambridge University Press.

Dietz, M., Khan, H., \& Rab, I. (2020). How do companies create value from digital ecosystems? Available online: https://www.mckinsey.com (accessed on 7 August 2020)

Fernandez-Vazquez, S., Rosillo, R., De La Fuente, D., \& Priore, P. (2019). Blockchain in FinTech: A Mapping Study. Sustainability, 11, 6366; doi: 10.339o/su11226366

Fisher, J., \& Rucki, K. (2017). Re-conceptualizing the Science of Sustainability: A Dynamical Systems Approach to Understanding the Nexus of Conflict, Development and the Environment. Sustainable development, 25: 267-275. DOI: 10.1002/sd.1656

Folke, C. (2016). Resilience (Republished). Ecology and Society, 21, 4: 44-50. https://doi.org/10.5751/ES-o9o88210444

Gallopin, G. (2006). Linkages between vulnerability, resilience and adaptive capacity. Global Environmental Change, 16: 293-303. https://doi.org/10.1016/j.gloenvcha.2006.02.004

Giddense, A. (1983). A contemporary critique of historical materialism. V. 1. Berkeley: University of California Press.

Giddense, A. (1984). The Constitution of Society: Outline of the Theory of Structuration // Berkeley: University of California Press.

Giddings, B., Hopwood, B., \& O'Brien, G. (2002). Environment, economy and society: fitting them together into sustainable development. Sustainable Development, 10: 187-196. DOI: 10.1002/sd.199

Gregurec, I., Tomicic-Furjan, M., \& Tomicic-Pupek, K. (2021). The Impact of COVID-19 on Sustainable Business Models in SMEs. Sustainability, 13, 1098. https://doi.org/10.3390/su13031098

Hodgson, G. (2015). Conceptualizing Capitalism: Institutions, Evolution, Future // Chicago: University of Chicago Press.

Iansiti, M., \& Levien, R. (2004). The Keystone Advantage: What the New Dynamics of Business Ecosystems Mean for Strategy, Innovation, and Sustainability. Harvard Business School Press: Boston, MA.

Körner, K., Schattenberg, M., \& Heymann, E. (2018). Digital economics. How AI and robotics are changing our work and our lives. Deutsche Bank Research, available online 14 May. https://www.dbresearch.com

Martynov, A. (2019). The Turn to Overall Sustainable Social Transformation: Does it Real? Preprints, 2018100148. http://www.10.20944/preprints201810.0148.v2

Martynov, A. (2020). Sustainable overall social transformation as a way of progress. Journal of Social Science Research, 16, 4: 126-139. https://doi.org/10.24297/jssr.v16i.8910

Martynov, A. (2021). Strategy of overall social development: the challenge of sustainability. Arts and Social Sciences Journal, 4, 2: 1-2. https://www.hilarispublisher.com/archive/assj-volume-12-issue-2-year-2021.html

Metcalfe, J. (1994). Competition, Fisher's Principle and increasing returns in the selection process. Journal of $\begin{array}{lllll}\text { Evolutionary } & \text { Economics, } & 4, & 4: & 327-346 .\end{array}$ https://econpapers.repec.org/article/sprjoevec/v_3a4_3ay_3a1994_3ai_3a4_3ap_3a327-46 
MGI. (2021). How companies capture the value of sustainability: Survey findings. Available at: https://www.mckinsey.com (accessed on 28 April 2021)

Moore, J. (1993). Predators and prey: a new ecology of competition. Harvard business review, 71, 3: 75-86. https://hbr.org/1993/o5/predators-and-prey-a-new-ecology-of-competition

Moore, J. (1996). The Death of Competition: Leadership \& Strategy in the Age of Business Ecosystems. Harper Business, New York.

Nelson, R., \& Winter, S. (1982). An Evolutionary Theory of Economic Change. Cambridge MA and London: Belknap Press of Harvard University Press.

North, D., Wallis, J., \& Weingast, B. (2009). Violence and social orders. N.Y.: Cambridge University Press.

OECD. (2019). Measuring Distance to the SDG Targets 2019: An Assessment of Where OECD Countries Stand. Paris: OECD Publishing.

OECD. (2020). Fostering economic resilience in a world of open and integrated markets. Available at: https://www.oecd.org/newsroom/OECD-G7-Report

Ostrom, E. (200o). Collective Action and the Evolution of Social Norms. Journal of Economic Perspectives, 14, 3: 137-158. https://www.aeaweb.org/articles?id=10.1257/jep.14.3.137

Ostrom, E. (2007). A diagnostic approach for going beyond panaceas. Proceedings of the National Academy of Sciences of the United States of America 104, 39: 15181-15187. https://doi.org/10.1073/pnas.0702288104

Parsons, T. (1968). The structure of social actions. New York: Free Press.

Partelow, S. (2018). A review of the social-ecological systems framework: applications, methods, modifications, and challenges. Ecology and Society, 23, 4: 36-44. https://doi.org/10.5751/ES- 10594-230436

Porter, M., \& Kramer, M. (2011). The big idea: Creating shared value. Harvard Business Review, 89: 62-77. https://hbr.org/2011/o1/the-big-idea-creating-shared-value

Pidun, U., Reeves, M., \& Schüssler, M. (2020). Why Do Most Business Ecosystems Fail? Available online: https://www.bcg.com/publications/2020 (accessed on 22 June 2020)

Sadollah, A., Nasir, M. \& Zong, W. G. (2020). Sustainability and Optimization: From Conceptual Fundamentals to Applications. Sustainability, 12, 2027, doi: 10.3390/su12052027

Sachs, J. (2015). The Age of Sustainable Development. New York: Columbia University Press.

Sachs, J., Schmidt-Traub, G., Kroll, G., Lafortune, C., \& Fuller, G. (2019). Sustainable Development Report 2019. New York: Bertelsmann Stiftung and Sustainable Development Solutions Network.

S\&P Global. (2021). The Sustainability Yearbook 2021. Available at: https: spglobal.com/yearbook

Sneader, K., \& Singhal, S. (2021). The next normal arrives: Trends that will define 2021 and beyond. Available online: https://www.mckinsey.com (accessed on 19 January 2021)

Spencer, H. (1885). The principles of sociology. New York: Appleton-Century-Crofts.

Tonis, R. (2015). SMEs Role in Achieving Sustainable Development. Journal of Economic Development, Environment and People. 4, 1: 26-35. http://jedep.spiruharet.ro

Transformation towards sustainable and resilient societies in Asia and in the Pacific. (2018). United Nations, Asian Development Bank, United Nations Development Program. Available at: http://sdgasiapacific.net/download/SDG_Resilience_Report.pdf

TWI2050 - the World in 2050. (2018). Transformations to Achieve the Sustainable Development Goals. Laxenburg: International Institute for Applied Systems Analysis.

TWI2050 - The World in 2050. (2019). The Digital Revolution and Sustainable Development: Opportunities and Challenges. Laxenburg: International Institute for Applied Systems Analysis.

WBGU - German Advisory Council on Global Change. (2019). Towards our Common Digital Future. Summary. Berlin: WBGU. 